\title{
Real-Time Determination of the Efficacy of Residual Disinfection to Limit Wastewater Contamination in a Water Distribution System Using Filtration-Based Luminescence
}

\author{
Jiyoung Lee ${ }^{1 *}$, Rolf A. Deininger ${ }^{2}$
}

\begin{abstract}
Water distribution systems can be vulnerable to microbial contamination through cross-connections, wastewater backflow, the intrusion of soiled water after a loss of pressure resulting from an electricity blackout, natiral disaster, or intentional contamination of the system in a bioterrorism event. The most urgent matter a water treatment utility would face in this situation is detecting the presence and extent of a contamination event in real-time, so that immediate action can be taken to mitigate the problem. The current approved microbiological detection methods are culture-based plate count methods, which require incubation time ( 1 to 7 days). This Iong period of time would not be useful for the protection of public health. This study was designed to simulate wastewater intrusion in a water distribution system. The objectives were 2-fold: (1) real-time detection of water contamination, and (2) investigation of the sustainability of drinking water systems to suppress the contamination with secondary disinfectant residuals (chlorine and chloramine). The events of drinking water contamination resulting from a wastewater addition were determined by filtration-based luminescence assay. The water contamination was detected by luminescence method within 5 minutes. The signal amplification attributed to wastewater contamination was clear-102-fold signal increase. After 1 bour; chlorinated water could inactivate $98.8 \%$ of the bacterial contaminant, while chloraminated water reduced $77.2 \%$. Water Environ. Res., 82 (2010).
\end{abstract}

KEXWORDS: water distribution systern, wastewater contamination, Juminescence, chlorine, chloramine.

doi: $10.2175 / 106143009 \times 12487095237035$

\section{introduction}

Water distribution systems may be vulnerable to contamination by various causes, such as cross-connections-the intrusion of

\footnotetext{
${ }^{1}$ Division of Environmental Health Sciences, Department of Food Science \& Technology, Ohio State University, Columbus, Ohio.

${ }^{2}$ Department of Environmental Health Sciences, University of Michigan, Ann Arbor, Michigan.

* Division of Environmental Health Sciences, Department of Food Science \& Technology, Ohio State University, Columbus, Ohio 43210; e-mail: jlee@cph.osu.edu.
}

soil-contaminated water through cracks when the pressure is not maintained (FCCCHR, 2004). Contamination of the drinking water supply by a deliberate injection of pathogens in a terrorist act is not unthinkable; however, in this case, overcoming the pressure of the system is required (AWWA, 1984; WHO, 1970). Extended blackouts tend to occur more often these days, partly because of extreme weather resulting from climate change. The extended power loss causes a pressure loss in water pipes, unless immediate backup power is provided. The pressure loss leads back-siphonage of water containing soil around the pipes into the water system through small fissures and leaking seals. When there are leaking sewers close to the water mains, the problem gets worse, because the wastewater may enter and be transported into the water mains after the water pressure is restored. The constant maintenance of disinfectant residual in the water distribution system is important in suppressing microbial contamination and controlling the bacterial regrowth in the water distribution system. For this reason, secondary disinfectant is added to the finished water before the water is distributed during the final step of water treatment at a water utility. Chlorine and chlorine-derived compounds, such as chloramine, which is made by combining chlorine and ammonia, are the only disinfectants known that can provide a continuous level of inactivation in a water distribution system. In the United States, this secondary disinfection is required by law for those water utilities required to disinfect their water (AWWA, 2009).

Water samples are tested regularly by water authorities for their water safety, to prevent possible consumption of contaminated water. R2A is the most commonly used standard method for enumerating drinking water bacteria recommended by the U.S. Environmental Protection Agency (APHA et al., 1998), because the diverse ingredients at low strength support the growth of injured bacteria in disinfectant-contained tap water, which has a low level of nutrients. It is known that R2A produces the greatest bacterial counts originating from the water supply compared with other agar plates (Reasoner et al., 1989). However, this culturebased method takes 3 to 7 days to get bacterial colony counts, as a result of the incubation period. Therefore, it is not possible to

Water Environment Research, Volume 82-Copyright $\odot 2010$ Water Environment Federation Uncorrected Page Proofs 
provide the timely results when a contamination event happens, and this delay can never meet the purpose of the water testing, which is protecting the public from the harmful consumption of deteriorated water. However, there are a few rapid detection methods that may be applied for examining bacterial levels in drinking water. A few of them use an adenosine triphosphate (ATP) bioluminescence-based method, but this detects the total bioluminescence of all possible ATP sources, such as yeast and molds, in addition to bacteria. Therefore, this method is more appropriate for measuring general surface hygiene (e.g., MoniTek, CLX Inc., Temecula, California) rather than determining bacterial contamination. There is hardly any method that can solely measure bacterial ATP. Most of the claimed rapid methods, including ATP bioluminescence methods and molecular technique-based methods, are not really "rapid", because they require a 12- to 48-hour enrichment step before their detection step (e.g., HybriScan, Sigma Aldrich [St. Louis, Missouri] and AKuScreen, Celsis [Chicago, nlinois]). As a result, a need remains for determining microbial contamination in drinking water systems near real-time. In this study, we used a filtration-based bioluminescence method for a near real-time $(<5$ minutes) measurement of bacterial levels. The filtration procedure allows concentrating bacteria, so that it lowers detection limits and eliminates an enrichment step. This method consists of four components-concentration, removal of non-bacterial cells and conditioning, lysis of bacterial cells, and integration of luminescence signals. The ATP released from lysed bacterial cells reacts with added luciferine/luciferase, which then develops light. The integrated light emission is measured with a microluminometer. The extent of the emitted light is proportional to the ATP amount, which is proportional to the bacterial numbers (Lee and Deininger, 1999,2004 ). In previous studies, the bacterial levels in drinking water estimated with ATP bioluminescence assay correlated well with the bacterial counts measured with the R2A method (Deininger and Lee; 2001; Meier et al., 2008). In this study, the drinking water contamination events were simulated by adding wastewater effluents to two different types of water, which had different disinfectant residuals (chlorine and chloramine). The effectiveness of the different disinfectant residuals in controlling bacterial contamination was examined during the first 2 hours of the contamination event, by using filtration-based bioluminescence as a near-real-time assessing tool. Thus, when an unexpectedly high signal is obtained using this filtration-based luminescence, further identification of bacterial species can be initiated, to verify the presence of pathogens.

\section{Methodology}

Simulation of Water Contamination. Water contamination events were simulated in our laboratory. For this study, water samples were obtained from two water treatment plants in southeast Michigan. Each water plant uses a different disinfectant (chlorine or chloramine). Wastewater samples were collected from the secondary wastewater effluent at a wastewater treatment plant in southeast Michigan. The water and wastewater samples were transported to the laboratory on ice immediately after collection, and the experiments were performed immediately. The concentration of the disinfectants was measured using a Hach. chlorine analyzer (Hach Company, Loveland, Colorado).

Based on our preliminary data (not shown), it was deternined that the filtration-based luminescence method is sensitive enough to detect a $1 \%(\mathrm{v} / \mathrm{v})$ addition of wastewater into drinking water. This amount of wastewater was used during the study period. In most cases, the experimental setup was spiking $5 \mathrm{~mL}$ of a wastewater sample into $500-\mathrm{mL}$ of a drinking water sample and then gently mixing using a magnetic stirrer. The same setup was used for each disinfectant-containing water sample (chloramine and chlorine). The baseline bacteria levels in the drinking water were measured by the rapid-filtration-based luminescence method before injection of wastewater. The contaminated water samples were analyzed immediately after the spiking of the wastewater ( 0 seconds) and during the time period of 2 hours at $1,5,10,20,40$, 60 , and 120 minutes. At each time interval, samples were drawn, and the bacterial concentrations were determined by the rapidfiltration-based luminescence method. All the measurements were done in triplicate. The rapid method results were available within 5 minutes. The data were compiled using Microsoft Excel (Microsoft Corporation, Redmond, Washington).

Filtration-Based Luminescence Procedure. The principle of bioluminescence is to quantify the ATP extracted from the bacterial cells collected from water samples. To remove the ATP source from nonbacterial cells that might be present in the water samples; the filtered samples were washed with $250 \mu \mathrm{L}$ somatic cell-releasing agent (SRA), according to the manufacturer's instructions (New Horizons Diagnostics, Columbia, Maryland). This SRA treatment not only removes nonbacterial cells, but also adjusts chemical conditions, such as $\mathrm{pH}$, for optimizing further the luminescence reaction, which is $\mathrm{pH}$-dependent. After the conditioning, the concentrated bacterial cells were lysed with $50 \mu \mathrm{L}$ bacterial cellreleasing agent (BRA) for ATP extraction. The extracted ATP was then mixed with $50 \mu \mathrm{L}$-luciferin/luciferase. The integrated light emission was measured with a microluminometer (integration time $=30$ seconds; New Horizons Diagnostics), and the results were recorded as relative light unit (RLUs). The final result was converted to RLU/mL after dividing by the volume of the water filtration. The combination of "membrane filter-cuvette" format enables this entire procedure, from the water concentration to the light emission integration, in a "single cuvette", thus minimizing sample loss. The principle of the light reaction between the ATP and the luciferin/ luciferase is as follows: LH2 (luciferin) $+\mathrm{E}$ (luciferase) $+\mathrm{ATP} \rightarrow \mathrm{E}$ LH-AMP (luciferyl adenylate complex) + PP (pyrophosphate), E$\mathrm{LH}-\mathrm{AMP}+\mathrm{O} 2 \rightarrow \mathrm{E}-\mathrm{L}-\mathrm{AMP}$ (dehydroluciferyl adenylate) + light (Qureshi and Patel, 1976). The activity of luciferin/luciferase is checked with the ATP standard solution (Sigma, St. Louis, Missouri) each time a set of experiments was performed. Deionized water was used as a negative control.

\section{Results and Discussion}

The hypothesis of this study was that the addition of wastewater would increase the level of microbes in the drinking water samples, but the presence of secondary disinfectant may be able to inactivate the microbial contaminant after certain period of contact time. Another aim was to compare the effectiveness of two commonly used secondary disinfectant residuals in these contamination events, and we expected that chlorine would perform better than chloramines, as a result of its oxidation property. After the water samples were contaminated with wastewater, the increased levels of bacteria were measured at 0 seconds (wastewater addition) and 1-, 5-, 10-, 20-, 40-, 60-, and 120-minute intervals. The chlorine concentration of the chlorinated water was 3.1 (total) and 2.9 (free) $\mathrm{mg} / \mathrm{L}$. The chlorine concentration of the chloraminated water was

Water Environment Research, Volume 82-Copyright (1) 2010 Water Environment Federation Uncorrected Page Proofs 


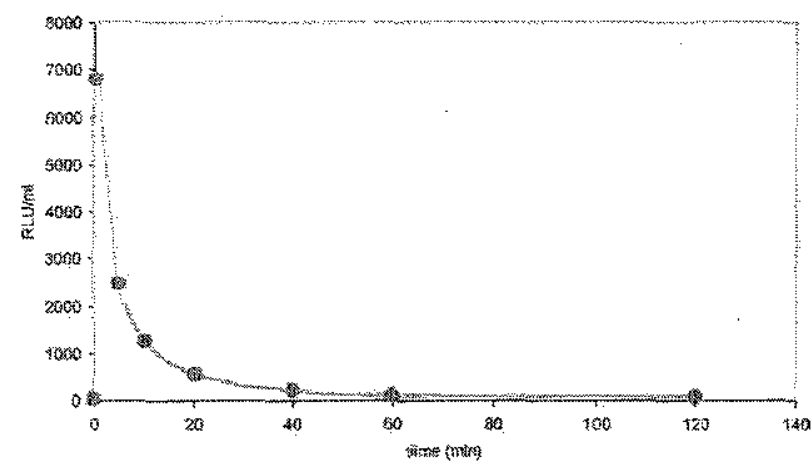

Figure 1-Measurement of the change of bacterial level resulting from wastewater contamination in chlorinated drinking water using filtration-based luminescence.

2.3 (total) and 0.3 (free) $\mathrm{mg} / \mathrm{L}$. The baseline concentrations of bacteria in water samples before the spiking of wastewater effluent were 48 (chlorinated water) and 84 (chloraminated water) RLU $/ \mathrm{mL}$, respectively. After the addition of the wastewater, the signal surged to $6812 \mathrm{RLU} / \mathrm{mL}$ in the chlorinated water and $4068 \mathrm{RLU} / \mathrm{mL}$ in the chloraminated water (Figures 1 and 2). This phenomenon showed that the wastewater contamination event can be detected clearly by the amplified signal of an approximately 102-fold increase using filtration-based luminescence in less than 5 minutes.

The extent of wastewater contamination in drinking water that could reasonably be detected by the filtration-based luminescence system was calculated mathematically using the $99 \%$ upper confidence interval of the baseline values. The standard deviation of the chlorinated water baseline (average $=48$ ) was 22.1 , and the confidence was 32.8 (alpha $=0.01$ ). Thus, chlorinated water has the upper limit of confidence interval of 81 , which corresponds to $0.0125 \%(\mathrm{v} / \mathrm{v})$ wastewater contamination. It is based upon the assumption of a linear correlation between the contamination level and the RLU value. Using the same statistical calculation, chloraminated water has the upper limit of 161 , and it corresponds to $0.04 \%(\mathrm{v} / \mathrm{v})$ wastewater contamination (average baseline $=84$, standard deviation $=52$, confidence $=77.3$, and alpha $=0.01$ ) .

From the simulated experiments, it was possible to investigate whether the sudden increase of bacterial levels coming from the wastewater contamination in the water distribution system can be controlled by the existing disinfectant residuals, which typically

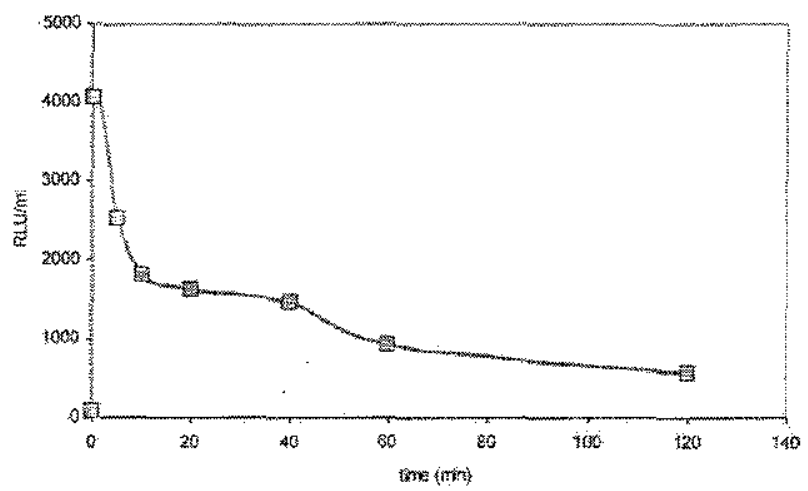

Figure 2-Measurement of the change of bacterial level resulting from wastewater contamination in chloraminated drinking water using filtration-based luminescence.

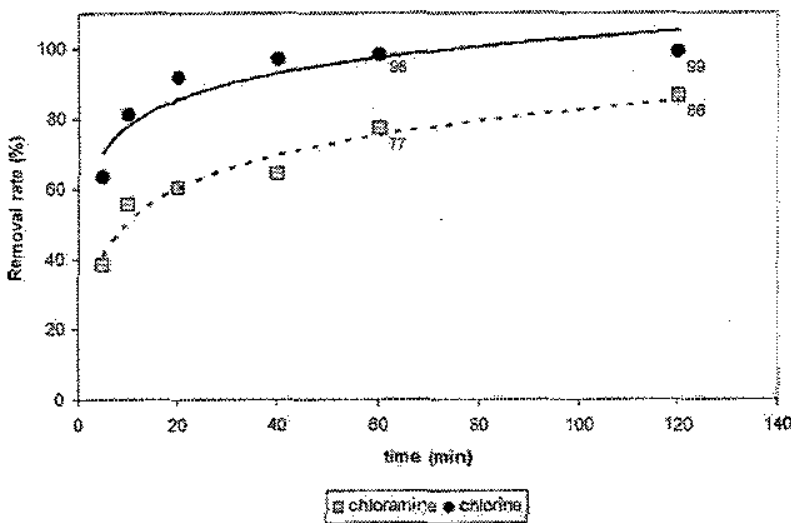

Figure 3-Comparison of the bacterial removal rate resulting from the two types of residual disinfectants in wastewater-contaminated drinking water.

are added in the form of secondary residual when the finished water leaves the water treatment plant. The amplified bacterial level started to decline as fast as within 5 minutes, when the residual type was chlorine, and, after 5 minutes, it removed $64 \%$ of the microbial contamination, which originated from the wastewater addition. The spiked bacterial contaminants became suppressed by the action of the disinfectant residuals with the efficiency of $98.8 \%$ (chlorine) and $86.2 \%$ (chloramine) inactivation within the 2-hour test duration (Figure 3 ). This also indicates that there is a difference in the effectiveness and speed of the action of the two different disinfectants. Chlorine was more effective and faster than chloramine in inactivating bacterial contaminants. For example, after 60 minutes, $98 \%$ of the increased level of the bacteria was removed by chlorine, while $77 \%$ of the bacterial contaminants were removed in the chloraminated water. This implies the significance of the constant maintenance of recommended disinfectant residual level in water distribution systems to prepare for events of accidental contamination. The result of the fate of contaminated bacteria in drinking water also shows that the bacterial levels can be determined by the rapid filtration-based luminescence in less than 5 minutes.

\section{Conclusions}

In conclusion, the increased level of bacterial levels in the public water supply resulting from wastewater contamination can be detected in less than 5 minutes, without an enrichment step, using the filtration-based luminescence. This method can serve as a pin-pointing response tool during abnormal events to determine the safety of water supply systems. The results clearly indicate that there exists a difference in the effectiveness between the two types of secondary disinfectants-chlorine and chloramine. Within the 120-minute period of the experiments, the increased level of bacteria resulting from the wastewater contamination was controlled with the removal rates of $86 \%$ (chloramine) and $99 \%$ (chlorine). This implies that it is crucial to maintain a disinfectant residual continuously throughout the water distribution system for the protection of our water supplies. The estimated degrees of wastewater contamination that could reasonably be detected by the filtration-based luminescence system are 0.0125 and $0.04 \%$ (v/ $v)$ in the chlorine- and chloramine-containing water distribution systems, respectively. 
Submitted for publication April 21, 2009; revised manuscript submitted September 7, 2009; accepted for publication September 8, 2009.

\section{References}

American Public Health Association; American Water Works Association; Water Environment Federation (1998) Stundards Methods for the Examination of Water and Wastewater, 20th ed.; American Public Health Association: Washington, D.C.

American Water Works Association (2009) Drinking Water Disinfection and Utility Choice of Disinfectant; Annerican Water Works Association: Denver, Colorado, http://www.awwa.org/files/Disinfection.pdf (accessed Feb. 3, 2009).

American Water Works Association (1984) Emergency Planning for Water Utility Management, Appendix A. The Threat from Addition of Chemical and Biological Agents to a Municipal Water Supply; American Water Works Association: Denver, Colorado, 55-64.

Deininger, R. A.; Lee, J. (2001) Rapid Determination of Bacteria in Drinking Water Using an ATP Assay. Field Anal. Chem. Technol., 5, 185-189.
Foundation for Cross-Connection Control and Hydraulic Research (2004) Prevalence of Cross-Connections in Household Plumbing Systems; University of Southern California: Los Angeles, California, http://www. usc.edu/dept/fecchr/epa/hhcc.report.pdf (accessed Feb. 3, 2009).

Lee, J.; Deininger, R. A. (2004) Detection of E.coli in Beach Water within $1 \mathrm{Hr}$ Using Immunomagnetic Separation and ATP Bioluminiscence. Luminescence, 19, 31-36.

Lee, J; Deininger, R. A. (1999) A Rapid Method for Detecting Bacteria in Drinking Water. J. Rapid Methods Auto. Microbiol, 7, 135-145.

Meier, T. M.; Maute, C. J.; Cadillac, J. M.; Lee, J.; Righter, D. J.; Hugunin, K. M. S.; Deininger, R. A.; Dysko, R. C. (2008) Quantification, Distribution and Possible Source of Bacterial Biofilm in Rodent Automated Watering Systems. J. Am. Assoc. Lab. Anim. Sci., 79, 1-9.

Qureshi, A. A.; Patel, J. (1976) ATP Levels in Mictobial Cultures and a Review of the ATP Biomass Estimation Technique, Scientific Series No. 63; Canada Center for Inland Waters: Burlington, Ontario, Canada.

Reasoner, D. J.; Blamnon, J. C.; Geldreich, E. E.; Barnick, J. (1989) Non Photosynthetic Pigmented Bacteria in a Potable Water Treatment and Distribution System. Appl. Environ. Microbiol., 55, 912-921.

World Health Organization (1970) Health Aspects of Chemical and Biological Weapons. Annex 5. Sabotage of Water Supplies. World Health Organization: Geneva, Switzerland, 113-120. 